\title{
GAETANO FERRO
}

\section{CARMINDA CAVACO ${ }^{1}$}

Com uma vida intensamente dedicada à investigação e ao ensino universitário, Gaetano Ferro tem o seu labor reconhecido fundamentalmente nos meios académicos². É membro efectivo da Academia Ligure de Ciências e Letras e da Academia Nacional dos Linces. Desde 1987 até muito recentemente foi Presidente da Sociedade Geográfica Italiana, de Roma.

Livre docente em 1958, obteve a Cátedra de Geografia na Faculdade de Letras da Universidade de Génova, em 1960. Depois foi também professor de Geografia Económica e de Geografia Histórica e das Explorações nas Universidades de Trieste e Comercial (Luigi Bocconi), de Milão. Atingiria o jubileu como "ordinário" de Geografia Política e Económica da Faculdade de Magistério e de Ciências Políticas de Génova, a cuja direcção presidiu durante vários anos.

Gaetano Ferro tem publicada uma vasta obra científica, que comporta três dezenas de livros e um grande número de artigos, e abrange quase todos os domínios da Geografia Humana, com incursões em ciências afins, nomeadamente a História e a Ciência Política. Numa tentativa de sistematização, podemos considerar cinco grandes domínios no seu labor científico: os estudos portugueses; os estudos referentes a Génova e à Ligúria; a Geografia Política e Histórica; os estudos sobre Cristovão Colombo, numa perspectiva geográfica; e ensaios de reflexão quanto à natureza da Geografia Humana.

As actividades de investigador e de pedagogo de Gaetano Ferro estão profundamente articuladas com a realidade portuguesa, através de intercâmbios que se iniciaram há mais de 40 anos, desde que, jovem investigador, com uma bolsa do Conselho Nacional para a Investigação, chega a Portugal em 1954, munido de alguns conhecimentos de português, que estudara em Génova. Começou então os seus estudos de Geografia do nosso país e em particular do Algarve, preparando a

\footnotetext{
1 Professora Catedrática da Faculdade de Letras, Universidade de Lisboa. Investigadora do Centro de Estudos Geográficos da Universidade de Lisboa. Centro de Estudos Geográficos, Faculdade de Letras, Letras, Cidade Universitária, 1699 LISBOA Codex. Tel: (351-1) 79402 18; fax (351-1) 793 86 90; E-mail: ceg@mail.telepac.pt.

2 Discurso proferido na cerimónia de atribuição do grau de Doutor Honoris Causa pela Universidade de Lisboa ao Professor Gaetano Ferro, realizada na Aula Magna da Reitoria, no dia 9 de Julho de 1997.
} 
sua tese de livre docência sob a orientação do Professor Orlando Ribeiro, o mestre para quem esta cerimónia responde a uma vontade de há muito expressa, e que com toda a simplicidade, tentarei substituir, retomando aqui e além alguns dos seus escritos a respeito deste seu antigo discípulo, muito amigo.

Diz Orlando Ribeiro: "Era eu então titular da cadeira de Geografia de Portugal, que costumava dividir numa parte geral e numa regional... Em atenção ao jovem colega italiano e em consenso com os alunos, dei uma série de aulas sobre o Algarve (...). Arrumámos logo uma excursão à Arrábida, nesga mediterrânea entre terras e águas atlânticas (...). Depois, quando me foi possível (...), partimos para o Algarve (...). Fizemos uma prospecção de conjunto que abrangeu Serra, Barrocal e Litoral, cidades, vilas e campo(...). Ao fim de cerca de uma semana, largámos Gaetano Ferro em Faro, que fez então a sua primeira e prolongada estada algarvia, onde várias vezes havia de voltar (...). Destas viagens e convívio resultou (...) uma indefectível simpatia humana e numerosos encontros na Itália e em Portugal (...). Nunca mais Ferro esqueceu a sua experiência portuguesa".

O Algarve constituiu então a região de trabalho eleita por Gaetano Ferro, traduzido na sua tese de doutoramento, sob a forma de valiosa monografia regional,e em muitos outros artigos, que constituem referências indispensáveis na compreensão da organização do seu povoamento, da sua rede urbana, das suas actividades económicas, da génese e evolução das suas paisagens. Alguns outros artigos surgiram bastante depois, numa perspectiva já comparativa com a Ligúria e a Sicília, territórios costeiros de ambiente mediterrâneo.

O Algarve e Portugal continuaram a ser para Gaetano Ferro terra amada, que foi visitando, observando as mutações socio-económicas e ambientais e promovendo o seu conhecimento, inclusive conduzindo viagens de estudo de grupos numerosos de colegas italianos. Foi durante uma destas viagens de estudo que tive a feliz oportunidade de conhecer pessoalmente Gaetano Ferro, autor que Orlando Ribeiro me levava a ler e a estudar por o considerar indispensável na formação e informação de quem se interessava pela geografia do Algarve, mesmo estando os seus escritos disponíveis apenas em italiano,convencendo-me justificadamente de que se tratava duma língua acessível após um esforço de leitura de alguns dias.

Gaetano Ferro pedira a Orlando Ribeiro o apoio de alguém que conhecesse o Algarve, nomeadamente as transformações mais recentes da sua geografia, e o Mestre indicou a sua jovem assistente, algarvia de naturalidade e de longa vivência e que iniciara há pouco uma tese de doutoramento também sobre a região. E lá fui eu, quase sem saber dizer uma palavra em italiano, acompanhar durante uma semana meia centena de notáveis professores de história e de geografia daquela nacionalidade. Foram uns dias muito agradáveis e cientificamente muito proveitosos. Desse convívio resultou a estima e amizade com que Gaetano Ferro me distingue desde essa altura, a sua co-orientação sábia e paciente da minha tese de doutoramento, a oportunidade de viagens de estudo a Itália e, nomeadamente, o estímulo ao meu então bem ousado interesse pela Geografia do ócio, do lazer e do turismo, através da concessão duma bolsa para investigação sobre uma parte da Riviera 
Ligure. Nesta ocasião, Gaetano Ferro proporcionou-me, no seu Instituto, o melhor acolhimento, iniciou-me no trabalho de campo com uma viagem de descoberta, introdutória, a toda a Riviera, reviu o meu texto original e assegurou por fim a sua publicação em livro, num excelente italiano.

Não cessou jamais a cooperação de Gaetano Ferro com o departamento de Geografia e o Centro de Estudos Geográficos, da Universidade de Lisboa, tanto no plano científico como no plano pedagógico. Também não cessaram os seus estudos portugueses, de que sublinhamos dois livros sobre as navegações: Os navegadores portugueses no Caminho da Índia (Milão 1974), com tradução portuguesa (1989), e As navegações lusitanas no Atlântico e Cristóvão Colombo em Portugal (Milão 1985).

Na sua vasta bibliografia desejamos destacar, pela sua importância, uma excepcional e inovadora obra de reflexão sobre a Geografia Humana: Geografia e liberdade: temas e problemas de geografia humana (1983).

Um grande número das suas publicações é dedicado a Génova e à Ligúria, abrangendo os mais variados campos da Geografia Humana, da estrutura industrial aos movimentos migratórios, com passagem por um tema recorrente - o da geografia das cidades. Eis alguns títulos de livros:As localizações industriais na bacia superior da Bormida (1959), Ligúria (1961), Contributos para a geografia urbana de Génova (1969), Movimentos da população na região ligure (1973), Savona e o seu ambiente (1975), A Ligúria e Génova no tempo de Colombo (1988), A emigração da província de Génova para a América (1990-91), Vado ligure no ano 2000 (1990).

A Geografia Política e a Geografia Histórica constituem outras áreas de pesquisa que atravessam todo o seu percurso científico, desde os primeiros estudos sobre o Algarve e Portugal. Uma referência particular é devida a um importante artigo, de 1964, sobre A fronteira de Portugal e a sua subdivisão regional. Mas as principais obras neste domínio são de natureza geral: Comunidade humana, limites políticos e administrativos (1979); e muito mais recentemente, Fundamentos de Geografia política e geopolítica. Política do território e do ambiente. Estudo de sintese (1993). Não se esqueça ainda o seu livro Sociedade humana e ambiente no tempo. Temas e problemas da geografia histórica (1974), onde Gaetano Ferro evidencia que "a geografia e a história, embora mantendo a sua própria individualidade, podem ser, com vantagem, ligadas numa visão cultural, na certeza de que o presente não pode ser compreendido sem o passado" e de que "aquilo que hoje é geografia, amanhã será história (...). A matéria geográfica passa assim continuamente à história, como os restos do passado, embora remoto, entram nas formas da vida do presente".

Tive o prazer de traduzir este último livro, assegurando a sua edição em português pela Fundação Calouste Gulbenkian. Esta foi prefaciada por Orlando Ribeiro. Deste seu prefácio, destaco: "Sociedade humana e ambiente, no tempo(...) constitui uma iniciação ao assunto - relações entre a Geografia e a História recomendável tanto aos estudantes de Geografia como de História, e com caracte- 
rísticas muito pessoais, que derivam da larga experiência e específica formação do autor (...). Ferro, que enveredou tarde pela geografia histórica, concedeu todavia, nos seus trabalhos anteriores, a maior importância ao passado que ilumina a compreensão do presente. Ele procura e consegue o que chamamos "ver no tempo" (...). São numerosas as alusões a factos portugueses; retoma uma comparação entre a Ligúria, a Sicília e o Algarve, estes com muitos pontos de contacto, aquela em posição setentrional que confere à sua geografia aspectos estranhos ao Mediterrâneo clássico (...). Especialmente importante (...) é o capítulo sobre o contributo da toponímia.(...). Gaetano Ferro não hesita em falar dos trabalhos e misérias do camponês mediterrâneo (...). A força da tradição na paisagem agrária mediterrânea é posta vigorosamente em evidência (...). A base de toda a Geografia Humana está no seu confronto com a natureza e com a história".

Gaetano Ferro fora aliás responsável pela edição em italiano de trabalhos de Geografia Humana de O. Ribeiro, assegurando-lhe a sua larga difusão entre os estudiosos do seu país.

Os estudos colombianos constituem uma orientação mais recente na obra de Gaetano Ferro, mas anunciada nas pesquisas que realizara sobre as navegações dos portugueses nos séculos XV e XVI. Entretanto a produção tem sido abundante e os resultados já se traduziram em várias publicações, de que assinalamos: Os lugares de Colombo no Velho Mundo (1988); Em busca de um imaginário e outras paisagens, outras plantas, outros animais (1991); A tradição cartográfica ligure e Cristóvão Colombo (1992). A consolidação desta linha de investigação levou, aliás, à criação do Centro Interdepartamental de Estudos Geográficos Colombianos, da Universidade de Génova, de que Gaetano Ferro foi fundador e permanece director. Este Centro organizou em 1994, por ocasião das cerimónias de imposição do título de Doutor Honoris Causa a Mário Soares, um Colóquio sobre Itália e Portugal, as coordenadas de uma renovada relação.

A relevância da carreira científica e académica e as ligações intensas e profícuas a Portugal e à Universidade de Lisboa, justificam plenamente a atribuição do grau de Doutor Honoris Causa pela mesma Universidade ao Professor Gaetano Ferro. 